\title{
Study of cotton seed term sowing territories in areas susceptible to wind erosion in Uzbekistan
}

\author{
Zokirjon Ismatullaev ${ }^{1}$, Allamurat Khojasov ${ }^{2}$, Gulnora Akhmedjanova ${ }^{3}$, Munisa Pulatova $^{3}$, \\ and Gafurjan Isaev ${ }^{4, *}$ \\ ${ }^{1}$ Scientific Research Institute of Cotton Breeding, Seed Production Agrotechnologies, Tashkent, \\ Uzbekistan \\ ${ }^{2}$ Nukus Branch of Tashkent State Agrarian University, Nukus, Karakalpakstan, Uzbekistan \\ ${ }^{3}$ Tashkent Institute of Irrigation and Agricultural Mechanization Engineers, Tashkent, Uzbekistan \\ ${ }^{4}$ Specialized School-Lyceum named after Yuriy Gagarin, Abay str., 60, Agadyr, Karaganda province, \\ Kazakhstan
}

\begin{abstract}
The cotton seeds of Namangan-77, Sultan, S-8290, and S-8286 varieties were sown on May 5 with N-200, P-150, K-100 mineral fertilizers and irrigated at $70-80-70 \%$ of LFMC. When the seeds were sown on May $15,58.4 \%$ of cotton was yielded in the first harvest from S-8286 compared to the above varieties. Compared to other varieties, an increase in yield in the first harvest was found to be 1.3-13.5\%. Namangan-77, Sultan, S-8290 and S-8286 varieties were sown on May 15 due to wind erosion and other natural disasters. Data on cotton yield of $28.0 \mathrm{q} / \mathrm{ha}$ are given.
\end{abstract}

\section{Introduction}

Uzbekistan is the northernmost cotton-growing country in the world. Due to the prevailing continental climate in Uzbekistan, cold weather occurs during sowing and germination of seeds, heavy rains cause the formation of crusts, strong winds blow away the seeds with soil, and cotton severely damages its growth point and leaves when it is still young [1-3]. Every year, as a result of these natural disasters, seeds are replanted or partially replanted on 100,000 hectares. In 2018, seeds were replanted on an area of 1,006 hectares in Fergana province of Uzbekistan. In particular, seeds were replanted on 288 hectares in Buvayda district, 133 hectares in Uchkuprik district, 93 hectares in Fergana district, 135 hectares in Yazyovan district and 175 hectares in Besharik district for various reasons [10-13]. Only on "Jamshidbek" farm in Besharik district, seeds sown on 25 hectares in 2018 were replanted due to strong wind erosion. In addition, several farms in the "Sobirtepa" MMTP area of the same district replanted seeds on 150 hectares as a result of a strong wind in April 2018.

As a result of deepening economic reforms in agriculture, the full transition of farming to the farming movement and the creation of all conditions and benefits created by the government for farms, as well as the creation of early-maturing varieties of cotton suitable for all soil and climatic conditions. The crop is harvested in October, but in some years, as a result of various natural disasters, many lands are replanted or partially replanted. In these

* Corresponding author: gafyrjon 007@,mail.ru 
cases, the cotton crop ripens late, causing serious damage to the crop and its quality $[14,15$, 17]. Therefore, in order to grow the intended crop of cotton on the lands where the seeds are replanted, it is necessary to plant short, fast-ripening varieties of cotton and develop and improve agrotechnologies for their cultivation. It is a confirmation of our opinion that the development of cotton has been delayed as a result of the cool arrival of spring, especially this year $[1-3,16]$.

Taking into account the soil and climatic conditions of Uzbekistan, many scientists have conducted extensive research on testing new varieties of cotton in any soil and climatic conditions, the development of agronomic techniques for growing abundant and highquality cotton [14-21]. However, in the Fergana Valley of Uzbekistan, insufficient research has been conducted to determine the timing of repeated or partial replanting of mediumfiber cotton varieties, to determine the norms of application of mineral fertilizers, to develop agrotechnology for high and quality cotton production through optimal irrigation.

The purpose of the study is to determine the timing of replanting or partial replanting of medium-fiber early-maturing cotton varieties in the Fergana Valley of Uzbekistan, to determine the norms of application of mineral fertilizers, to develop agrotechnology for high and quality cotton production through optimal irrigation.

\section{Materials and methods}

The object of research is the meadow-soil soils of Fergana province, Namangan-77, Sultan, S-8286, and S-8290 cotton varieties, sowing dates - April 15, May 5 and May 15, water and food standards.

The subject of the study is the meadow-soil soils of Fergana province, Namangan-77, Sultan, S-8286, S-8290 cotton sowing dates are April 15, May 5 and May 15, water and nutrition standards, its growth, development, productivity, fiber quality indicators and costeffectiveness.

Field and laboratory analyses were conducted according to "Methods for conducting experiments with cotton" [4], "Methods of agrochemical analyzes of soils and plants" [5], "Methods of agrophysical research" adopted at the Scientific Research Institute of Agrotechnology Research [6], and "Methods of conducting field experiments" [7] manuals. In the field of agrochemical analysis in the experimental field were dug 1-1.5 $\mathrm{m}$ of soil sections in the form of envelopes, soil samples were taken from genetic layers and the amount of humus in the soil was changed by IV Tyurin, total nitrogen and phosphorus AF Gritsenko, IM Maltseva, nitrate nitrogen Grandvald-Lyaju, the amount of reactive phosphorus was determined by the method of BP Machigin, the volume mass of the soil (SN Rijov) was determined by the cylindrical method, and the structure was determined by the method of IV Savvinov, [8-13],

\section{Results and discussion}

The mechanical composition of the meadow-soil soils of Fergana province, which was studied, determines its ability to increase or decrease all physical, physico-mechanical, volume, mass, porosity, and water permeability, as well as viscosity, resistance to tractor plows. The mechanical composition of the soil is loose sand, sticky sand, light, medium and heavy sands, the latter being in the case of heavy sands. The most agronomically convenient is medium sand (Table 1). 
Table 1. Mechanical composition of experimental field soils, $\%$.

\begin{tabular}{|c|c|c|c|c|c|c|c|c|}
\hline $\begin{array}{c}\text { Soil layer, } \\
\text { cm }\end{array}$ & $1-0.25$ & $\begin{array}{c}0.25- \\
0.1\end{array}$ & $\begin{array}{l}\text { 0.1- } \\
0.05\end{array}$ & $\begin{array}{l}0.05- \\
0.01\end{array}$ & $\begin{array}{l}\text { 0.01- } \\
0.005\end{array}$ & $\begin{array}{l}\text { 0.005- } \\
0.001\end{array}$ & $<0.001$ & $<0.1$ \\
\hline $0-30$ & 19.958 & 1.234 & 41.514 & 17.92 & 5.926 & 9.948 & 7.424 & 23.316 \\
\hline $30-50$ & 22.064 & 0.298 & 34.528 & 23.904 & 5.596 & 11.068 & 7.712 & 24.376 \\
\hline $50-70$ & 21.614 & 0.274 & 41.168 & 26.332 & 8.82 & 12.748 & 9.044 & 30.612 \\
\hline $70-100$ & 12.636 & 0.152 & 35.004 & 21.172 & 10.244 & 12.292 & 8.38 & 30.916 \\
\hline
\end{tabular}

The volumetric mass of the soil determines its softness. The volume of the mass varies with respect to the mechanical composition of the soil, the amount of humus in it, the macro and microstructure, manic, sandy horizons, gypsum, carbonate layers. If the mechanical composition is medium sand, water-resistant macro and microstructure, humus is abundant, the volume mass is improved. The aggravation of the mechanical composition makes the bulk mass of the clayey, carbonate, gypsum carbonate horizons in poor condition. The volume mass of the soil for optimal plant growth is $1.1-1.2 \mathrm{~g} / \mathrm{cm}^{3}$; the mechanical composition can be $1.3 \mathrm{~g} / \mathrm{cm}^{3}$ in light soils (Table 2).

Table 2. Volume weight of soil.

\begin{tabular}{|c|c|c|c|c|c|c|c|}
\hline \multirow{4}{*}{ 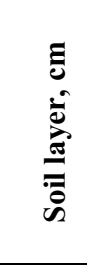 } & \multirow{4}{*}{ 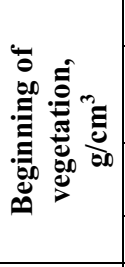 } & \multicolumn{6}{|c|}{ End of vegetation } \\
\hline & & \multicolumn{2}{|c|}{ First sowing term } & \multicolumn{2}{|c|}{ Second sowing term } & \multicolumn{2}{|c|}{ Third sowing term } \\
\hline & & $60-70-60$ & $70-80-70$ & $60-70-60$ & $70-80-70$ & $60-70-60$ & $\begin{array}{c}70-80- \\
70\end{array}$ \\
\hline & & \multicolumn{6}{|c|}{$\mathrm{g} / \mathrm{cm}^{3}$} \\
\hline $0-30$ & 1.18 & 1.25 & 1.25 & 1.24 & 1.24 & 1.24 & 1.24 \\
\hline $0-50$ & 1.28 & 1.31 & 1.33 & 1.28 & 1.28 & 1.31 & 1.31 \\
\hline $0-70$ & 1.33 & 1.32 & 1.34 & 1.31 & 1.30 & 1.35 & 1.35 \\
\hline $0-100$ & 1.34 & 1.32 & 1.34 & 1.30 & 1.30 & 1.34 & 1.34 \\
\hline
\end{tabular}

During the first and subsequent sowing periods, the topsoil was considered acceptable in terms of bulk density, and the subsoil was overgrown. As the volume of the soil increased, the porosity of the soil also decreased. The most optimal porosity was manifested in the drive layer of the soil.

The germination rate of the seed is described. In the Namangan-77 variety of cotton, 15 days were required for $88-91 \%$ germination when planted on April 19, 10 days were required for $84-88 \%$ germination when planted on May 5, and 8 days were required for $85-$ $93 \%$ germination when planted on May 19. The germination of seeds of Sultan, S-8290 and S-8286 varieties also showed close to Namangan-77 variety in accordance with the sowing dates. In general, seed germination was satisfactory, taking into account the sole (Table 3). 
Table 3. Germination of seeds sown at different times, \%.

\begin{tabular}{|c|c|c|c|c|c|c|c|c|}
\hline \multirow{2}{*}{$\begin{array}{l}0 \\
0 \\
0 \\
0\end{array}$} & \multirow{2}{*}{$\begin{array}{c}\text { Cotton } \\
\text { varieties }\end{array}$} & \multirow{2}{*}{ 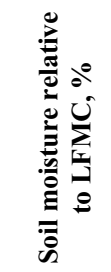 } & \multicolumn{2}{|c|}{ First sowing term } & \multicolumn{2}{|c|}{ Second sowing term } & \multicolumn{2}{|c|}{ Third sowing term } \\
\hline & & & Germination & $\%$ & Germination & $\%$ & Germination & $\%$ \\
\hline 1 & \multirow{6}{*}{ Namangan -77} & \multirow{3}{*}{$60-70-60$} & 3.05 & 88 & 16.05 & 85 & 27.05 & $\begin{array}{l}8 \\
5\end{array}$ \\
\hline 2 & & & 3.05 & 90 & 16.05 & 87 & 27.05 & $\begin{array}{l}9 \\
2\end{array}$ \\
\hline 3 & & & 3.05 & 91 & 16.05 & 88 & 27.05 & $\begin{array}{l}9 \\
3\end{array}$ \\
\hline 4 & & \multirow{3}{*}{$70-80-70$} & 3.05 & 90 & 16.05 & 84 & 27.05 & 8 \\
\hline 5 & & & 3.05 & 91 & 16.05 & 84 & 27.05 & $\begin{array}{l}8 \\
6\end{array}$ \\
\hline 6 & & & 3.05 & 91 & 16.05 & 86 & 27.05 & $\begin{array}{l}8 \\
8\end{array}$ \\
\hline 7 & \multirow{6}{*}{ Sultan } & \multirow{3}{*}{$60-70-60$} & 3.05 & 84 & 16.05 & 81 & 27.05 & $\begin{array}{l}8 \\
5\end{array}$ \\
\hline 8 & & & 3.05 & 85 & 16.05 & 82 & 27.05 & 8 \\
\hline 9 & & & 3.05 & 87 & 16.05 & 81 & 27.05 & $\begin{array}{l}8 \\
2\end{array}$ \\
\hline $\begin{array}{l}1 \\
0\end{array}$ & & \multirow{3}{*}{$70-80-70$} & 3.05 & 91 & 16.05 & 90 & 27.05 & $\begin{array}{l}8 \\
3\end{array}$ \\
\hline $\begin{array}{l}1 \\
1\end{array}$ & & & 3.05 & 95 & 16.05 & 91 & 27.05 & $\begin{array}{l}8 \\
9\end{array}$ \\
\hline $\begin{array}{l}1 \\
2 \\
\end{array}$ & & & 3.05 & 89 & 16.05 & 95 & 27.05 & $\begin{array}{l}9 \\
0 \\
\end{array}$ \\
\hline $\begin{array}{l}1 \\
3\end{array}$ & \multirow{6}{*}{ S-8286 } & \multirow{3}{*}{$60-70-60$} & 3.05 & 86 & 16.05 & 81 & 27.05 & $\begin{array}{l}8 \\
5\end{array}$ \\
\hline $\begin{array}{l}1 \\
4\end{array}$ & & & 3.05 & 88 & 16.05 & 82 & 27.05 & $\begin{array}{l}8 \\
8\end{array}$ \\
\hline $\begin{array}{l}1 \\
5\end{array}$ & & & 3.05 & 89 & 16.05 & 84 & 27.05 & $\begin{array}{l}8 \\
4\end{array}$ \\
\hline $\begin{array}{l}1 \\
6\end{array}$ & & \multirow{3}{*}{$70-80-70$} & 3.05 & 82 & 16.05 & 81 & 27.05 & $\begin{array}{l}9 \\
2\end{array}$ \\
\hline $\begin{array}{l}1 \\
7 \\
\end{array}$ & & & 3.05 & 85 & 16.05 & 85 & 27.05 & $\begin{array}{l}8 \\
5 \\
\end{array}$ \\
\hline $\begin{array}{l}1 \\
8\end{array}$ & & & 3.05 & 84 & 16.05 & 86 & 27.05 & $\begin{array}{l}8 \\
8 \\
\end{array}$ \\
\hline $\begin{array}{l}1 \\
9\end{array}$ & \multirow{6}{*}{ S-8290 } & \multirow{3}{*}{$60-70-60$} & 3.05 & 91 & 16.05 & 86 & 27.05 & $\begin{array}{l}8 \\
7\end{array}$ \\
\hline $\begin{array}{l}2 \\
0\end{array}$ & & & 3.05 & 92 & 16.05 & 92 & 27.05 & $\begin{array}{l}8 \\
9\end{array}$ \\
\hline $\begin{array}{l}2 \\
1\end{array}$ & & & 3.05 & 95 & 16.05 & 93 & 27.05 & $\begin{array}{l}9 \\
3\end{array}$ \\
\hline $\begin{array}{l}2 \\
2\end{array}$ & & \multirow{3}{*}{$70-80-70$} & 3.05 & 88 & 16.05 & 89 & 27.05 & $\begin{array}{l}9 \\
1\end{array}$ \\
\hline $\begin{array}{l}2 \\
3\end{array}$ & & & 3.05 & 88 & 16.05 & 88 & 27.05 & $\begin{array}{l}8 \\
9 \\
\end{array}$ \\
\hline $\begin{array}{l}2 \\
4\end{array}$ & & & 3.05 & 86 & 16.05 & 90 & 27.05 & $\begin{array}{l}9 \\
3\end{array}$ \\
\hline
\end{tabular}

According to the developmental stages of cotton, the correct setting of irrigation times and timely irrigation is a guarantee of higher yields. The earlier the cotton is watered before 
flowering, the taller it will grow and the more horns it will throw to the side. Yield nodules appear on the upper joints-branches of the tubers. It has been found that this slows down the ripening of the pods and delays the harvest. Proper watering of cotton until the flowering period leads to its rhythmic growth and flowering, well-developed root system and high yields.

Irrigation periods of cotton were determined on the basis of pre-water soil moisture specified in the program. As soon as the soil moisture reached the set level, the ground was given the next water.

Pre-irrigation soil moisture according to irrigation regimes led to differences in irrigation, norm, and amount of seasonal irrigation. Differences in irrigation regimens and norms, in turn, had different effects on the biological properties and early ripening of cotton. Cotton varieties planted in all periods were watered 3 times in a 1-1-1 system, in the order of $60-70-60 \%$. In one irrigation $1,100-1,191 \mathrm{~m}^{3} / \mathrm{ha}$, during the season $3,410-3,240$ $\mathrm{m}^{3} /$ ha, irrigation duration was 25-32 hours, irrigation interval was $18-21$ days, $70-80-70 \%$ in the order 1-2-1 system watered 4 times. Each irrigation was given $770-890 \mathrm{~m}^{3} / \mathrm{ha}, 3,535$ $-4,527 \mathrm{~m}^{3} /$ ha during the season, the duration of irrigation was $21-30$ hours, the interval between irrigations was 13-22 days.

Optimal sowing time is one of the decisive factors in determining the growth, development, harvesting and yield of cotton. It was observed that the formation of yield nodules and hollow pods depends mainly on soil conditions and water-nutrient norms, as well as planting times, depending on the specific biological characteristics of the cultivated variety. In our experiment, each cotton variety was studied at the same, theoretical seedling thickness of 90,000 bushes/ha, which was found to be acceptable for these varieties based on their biological properties, so as not to expand the workload. The purpose of determining the seedling thickness in the experiment is to prove that the additional cotton yield is not related to the seedling thickness, as well as to create conditions for the emergence of more yielding nodules in the studied cotton varieties and to obtain high quality cotton. It should be noted that after the full germination of cotton seedlings, 6-7 seedlings per meter were left in the $60 \times 15 \times 1-2$ system. In the experimental options, along with the calculation of the growth, development and growth organs of the cotton bush, the number of yield nodes in it was also recorded. It should be noted that it was found that irrigation regimes and fertilizer standards have a significant impact on the change in cotton weight per unit area.

During the first sowing period, the irrigation regime of Namangan-77 variety is $60-70$ $60 \%$ of the limited field moisture capacity (LFMC), fertilizers N-150; P-105; K-75 kg/ha, the weight of cotton in the pod is $4.6 \mathrm{~g}$, fertilizer standards are N-200; P-150; and with an increase of K-100 kg/ha, these figures were $5.1 \mathrm{~g}$. At the same time there was a decrease of $0.5 \mathrm{~g}$ compared to low fertilizer standards. The soil moisture of this variety is $70-80-70 \%$ from LFMC and fertilizers N-200; P- 150; K-100 kg/ha was applied, the weight of one piece of cotton was $5.2 \mathrm{~g}$.

The highest rate in the Sultan variety was observed in option 13, the irrigation regime was $70-80-70 \%$ from LFMC, fertilizers N-200; P-150; When K-100 kg/ha was used in the norm, it was $6.6 \mathrm{~g}$. This figure is $1.4 \mathrm{~g}$ more than the Namangan-77 variety.

Irrigation regime of S-8286 variety is $60-70-60 \%$ from LFMC, fertilizers N-150; P-105; $\mathrm{K}-75 \mathrm{~kg} / \mathrm{ha}$, the proportion was $5.0 \mathrm{~g}$. Fertilizer standards N-200; P-150; and with an increase in $\mathrm{K}-100 \mathrm{~kg} / \mathrm{ha}$, these figures were $5.3 \mathrm{~g}$. It differed by $0.3 \mathrm{~g}$ compared to low fertilizer standards. The soil moisture of this variety is $70-80-70 \%$ from LFMC and fertilizers N-200; P- 150; K-100 kg/ha, the weight was $4.9 \mathrm{~g}$. In the S-8290 cotton variety, the highest values are observed at high fertilizer and high water standards, the irrigation regime is $70-80-70 \%$ from LFMC, fertilizer N-200; P-150; K-100 kg/ha was $5.5 \mathrm{~g}$ when used normally. During this sowing period, a predominance of $6.6 \mathrm{~g}$ in the Sultan variety 
was observed in the weight of one bush. In the second and third sowing periods, when all agronomic measures were applied, the Sultan variety was 5.2-5.5 g. It can be seen that as the sowing period was delayed, the weight of one bush decreased. This is the case in the remaining varieties Namangan-77 (5.2-4.5-4.5 g), S-8286 (5.3-4.9-4.9 g), S-82-90 (5, 74.9-4.9 g) were also observed.

Thus, the sowing period - the growth, development of cotton varieties and the number of stalks, the weight of one stalk of cotton, the total weight of cotton per plant are proportional to each other, which is reflected in the weight of the cotton crop.

Irrigation regime of Namangan-77 cotton variety planted in the experiment is 60-70$60 \%$ of LFMC, mineral fertilizers N-150; P-105; K-75 kg/ha, the cotton yield was 28.9 quintal (q)/ha in proportion to the studies when planted on 15 April. When planted on May 5 , it was $27.6 \mathrm{q} / \mathrm{ha}$, and on May 15 it was $25.3 \mathrm{q} / \mathrm{ha}$. When the rate of mineral fertilizers was increased, the cotton yield was 30.3 tons/ha in the first period, 29.4 tons/ha in the second period and 27.3 tons/ha in the third period. It can be seen that with the increase in fertilizer rates, the yield also increased, with $1.4 \mathrm{q} / \mathrm{ha}$ in the first sowing period, $1.8 \mathrm{q} / \mathrm{ha}$ in the second sowing period, and $2.0 \mathrm{q} / \mathrm{ha}$ in the third sowing period. When the irrigation regime of Namangan-77 was increased to $70-80-70 \%$ of LFMC, the yield increased as the norms of mineral fertilizers increased. At the same time, 34.4 tons/ha was harvested in the first period, 33.0 tons/ha in the second period and 26.3 tons/ha in the third period. It can be seen that no matter how much water and nutrient standards are applied, the yield of cotton has decreased as the planting period has been delayed. The same situation was observed in Sultan, S-8286, and S-8292 varieties.

The aim of the research was to determine which variety could be planted when seeds were replanted for various reasons. Therefore, in the first harvest, we identified the most productive variety. During the first sowing period in Namangan -77 cultivars $55.8-61.1 \%$, Sultan cultivars $57.3-62.3 \%$, S-8286 cultivars $66.3-73.3 \%$, S- 8290 cultivars $66.3-61,6 \%$ of the crop was harvested in the first harvest. $47.1-56.2 \%$ of Namangan-77, $50.3-55.9 \%$ of Sultan variety, $58.5-63.8 \%$ of S-8286 variety, $67.7-66 \%$ of S-8290 variety planted in the second period, $8 \%$ of the crop was harvested in the first harvest. $44.9-49.4 \%$ of Namangan77 cultivars, $47.7-51.3 \%$ of Sultan cultivars, $57.1-51.1 \%$ of S-8286 cultivars and 52.6$58.4 \%$ of S- 8290 cultivars planted in the third period. \% of the crop was harvested in the first harvest. It can be seen that S-8286 and S-8290 varieties showed faster ripening than Namangan-77 and Sultan navigation during all planting periods.

Another important aspect is that the care of cotton in high fertilizer and moisture at late planting times has led to further delays in yield. Soil moisture in S-8286 variety is 60-70$60 \%$ from LFMC, fertilizer N-200; P-105; K-75 kg/ha, $28.2 \mathrm{q} / \mathrm{ha}$, soil moisture is $70-80$ $70 \%$ from LFMC, fertilizers N-200; P-105; K-75 kg/ha was used in moderation, the yield was less than $26.5 \mathrm{q} / \mathrm{ha}$, or $1.7 \mathrm{q} / \mathrm{ha}$. This indicator was more pronounced in Namangan-77 and Sultan varieties.

\section{Conclusions}

In areas where wind erosion and other natural disasters are observed, it is planted in three periods, two different irrigation regimes $(60-70-60 ; 70-80-70 ; \%)$ and three different fertilizer rates (N-150, P-105, K-75; N-175, P-125, K-80; N-200, P-140, K-100) are studied late and the following conclusions were drawn from experiments on the cultivation of highquality cotton from replanted cotton.

When the seeds were sown on May 15, 58.4\% of cotton was yielded in the first harvest from S-8286 compared to the above varieties. Compared to other varieties, an increase in yield in the first harvest was found to be $1.3-13.5 \%$. 
Seeds of Namangan-77, Sultan, S-8290 and S-8286 varieties were sown on May 15 due to wind erosion and other natural disasters. It was determined that the cotton yield will be $28.0 \mathrm{q} / \mathrm{ha}$.

This research work was carried out in the framework of the 5th priority area of development of science and technology of Uzbekistan entitled "Agriculture, biotechnology, ecology and environmental protection", as well as the Fergana experimental station of the Scientific Research Institute of Cotton Breeding, Seed Production and Agrotechnology.

\section{References}

1. N. Teshaev, B. Mamadaliyev, A. Ibragimov, S. Khasanov, InterCarto. InterGIS, 26(3), 324-333 (2020)

2. R. A. Kulmatov, S. A. Adilov, S. Khasanov, IOP Conf. Ser.: Earth Environ. Sci., 614(1), 012149 (2020)

3. A. Jumanov, S. Khasanov, A. Tabayev, G. Goziev, U. Uzbekov, E. Malikov, IOP Conf. Ser.: Earth Environ. Sci., 614(1), 012150 (2020)

4. Methods of agrochemical, agrophysical and microbiological studies in irrigated lands, 439 (Mekhnat Press, Tashkent, 2013)

5. Methods of agrophysical studies, 245 (Navruz Press, Tashkent, 2003)

6. Methods of agrochemical analysis of soil and plants, 301 (TashPITI Press, Tashkent, 2007)

7. Mehtods of conducting field experiments, 148 (Mekhnat Press, Tashkent, 2007)

8. Cotton reference book, 252 (Mehnat Press, Tashkent, 2009)

9. Reference of cotton production, 539 (Science and Technologies Press, Tashkent, 2016)

10. I. Aslanov, S. Khasanov, Y. Khudaybergenov, M. Groll, Ch. Opp, F. Li, E. Ramirez Del-Valle, E3S Web Conf., 227, 02005 (2021)

11. Y. Peng, F. Li, N. Xu, R. Kulmatov, K. Gao, G. Wang, Y. Zhang, Y. Qiao, Y. Li, H. Yang, S. Hao, Q. Li, S. Khasanov, Chinese Journal of Eco-Agriculture, 29(2), 312-324 (2021)

12. B. Sh. Matyakubov, Z. J. Mamatkulov, R. K. Oymatov, U. N. Komilov, G. E. Eshchanova, InterCarto, InterGIS, 26, 229-239 (2020)

13. Z. Mamatkulov, E. Safarov, R. Oymatov, I. Abdurahmanov, M. Rajapbaev, E3S Web Conf., 227, 03001 (2021)

14. N. Sabitova, O. Ruzikulova, I. Aslanov, E3S Web Conf., 227, 03003 (2021)

15. SH. Kenjabaev, H. G. Frede, I. Begmatov, S. Isaev, B. Matyakubov, Journal of Critical Reviews, 7(5), 340-349 (2020)

16. S. Isaev, SH. Mardiev, Z. Qodirov, Journal of Critical Reviews, 7(6), 245-249 (2020)

17. S. Isaev, A. Jumanov, M. Avlakulov, A. Tabaev, E. Malikov, Journal of Critical Reviews, 7(9), 148-154 (2020)

18. S. Isaev, B. Haydarov, S. Zakirova, Journal of Critical Reviews, 7(12), 304-309 (2020)

19. S. Isaev, Y. Ashirov, U. Sultanov, Journal of Critical Reviews, 7(12), 168-174 (2020)

20. S. Isaev, I. Begmatov, G. Goziev, S. Khasanov, IOP Conf. Ser.: Mater. Sci. Eng., 883(1), 012080 (2020)

21. S. K. Isaev, R. U. Rakhmonov, S. S. Tadjiev, G. I. Goziev, S. Z. Khasanov, IOP Conf. Ser.: Earth Environ. Sci., 614(1), 012147 (2020) 